\section{Magnetic variation anomalies in northern England and southern Scotland}

\section{R. J. Banks, D. Beamish* \& M. J. Geake}

Department of Environmental Sciences, University of Lancaster, Lancaster LAI 4 YQ, UK

* Geomagnetism Unit, Institute of Geological Science,

Murchison House, West Mains Road, Edinburgh EH9 3LA, UK

Single-station transfer functions linking the time variations of the vertical and horizontal components of the magnetic field at stations in northern England and southern Scotiand have been compiled into a uniform data set. From hypothetical event analysis we show here that there are two distinct anomalies in the Borders region. One runs south-west to north-east, immediately to the south-east of the Southern Uplands Fault; the second follows the Northumberland Basin, and seems to exist because the conductive sedimentary rocks filling the basin create a link between the Irish and North Seas. If the Iapetus suture is marked by a conductivity anomaly, as has been suggested $^{1.2}$, these results place it beneath the Southern Uplands, unless it is masked by the surface conductor in the Northumberland Basin.

During the past $10 \mathrm{yr}$, several Geomagnetic Deep Sounding investigations of the electrical structure of the crust and upper mantle of southern Scotland and northern England have been described $^{3-5}$. The area which they cover in most detail is the Southern Uplands and the northern part of the Northumberland Basin. We have accumulated a large body of similar data covering northern England and the Borders-as yet unpublished ${ }^{6}$. Because of the importance which the area has acquired in reconstructions of the events associated with the closure of the Iapetus Ocean ${ }^{7}$, it seems desirable to reduce the data to a common form, so that a picture of the conductive structure of the entire region can be presented.

The only common form in which the data are available is as single-station transfer functions, linking the vertical and horizontal components of the magnetic field variations at specific frequencies, at each site ${ }^{8}$. Our results indicate that, in the period range $10-10^{4} \mathrm{~s}$, transfer functions for the north of England are influenced by the magnetic fields associated with three different modes of induced current flow. At periods greater than $2,000 \mathrm{~s}$, they depend on the direct fields of currents flowing in the Atlantic Ocean and in the shallow seas around the British Isles. Between 300 and 1,500 s, the fields at many sites are produced by the perturbation of currents driven through the land as part of a thin-sheet induction process which includes the shallow seas. At periods $<100 \mathrm{~s}$, the transfer functions of sites which are sufficiently well insulated from conducting pathways between the seas detect currents produced by local induction in isolated regions of high conductivity. The largest data set that we could generate was at a period of $750 \mathrm{~s}$ and consisted of results from 94 stations; we anticipate that it will provide a picture of anomalous current concentrations in the shallow seas and, of more importance to us, in conductive 'links' in the land between them.

The technique that we have chosen to present the data is hypothetical event analysis ${ }^{9}$. In this approach, the single-station transfer functions are used to predict the vertical field of anomalous currents which would be produced when the horizontal component of the magnetic field across the region is spatially uniform, and has a specified polarization and intensity. Unfortunately, the prediction is wholly accurate only when the anomalous horizontal fields of the internal currents are negligible in comparison with the normal field. The presence of anomalous horizontal fields biases downwards the vertical fields computed using single-station transfer functions. In this case, we are forced either to accept the bias, or to discount any attempt to present a joint analysis of the data, as no other response measures are available for the area as a whole. However, at 35 stations on and around the Alston Block, inter-station transfer functions have been computed relative to a reference site at Durham (Fig. 1). The differences between the horizontal fields over this array and those at Durham, at a period of $750 \mathrm{~s}$, rarely exceed $20 \%$ of the average value. Nonetheless, the knowledge that the bias exists should make us very cautious in interpreting the data, particularly in attempting to draw quantitative inferences from the hypothetical event maps.

Figure 1 shows the distribution of sites in relation to the major structures in the crust which are likely to influence the flow of induced current. The granite batholiths should act as resistive blocks around which the current will be deflected, while it will be concentrated by the sedimentary basins.

The direction of the horizontal magnetic field which maximizes the anomalous vertical fields across the area as a whole is very close to magnetic north-south, and the anomalies are most strongly developed in the part of the vertical field which is in-phase with the horizontal. Figure 2 shows a contour map of the in-phase vertical field associated with a northward horizontal field of unit amplitude. The expected direction of the regional current flow for this azimuth of the magnetic field is from east to west. Note that a uniform regional current of this kind, whether it is restricted vertically or distributed with depth, produces no vertical field; the observed anomalous field is entirely due to the perturbations in the flow which are created by horizontal contrasts in conductivity. If we assume that the anomalous currents are concentrated in a thin sheet at a specific depth, the current stream function can be calculated directly from the map of anomalous vertical fields ${ }^{10}$. Figure 3 shows

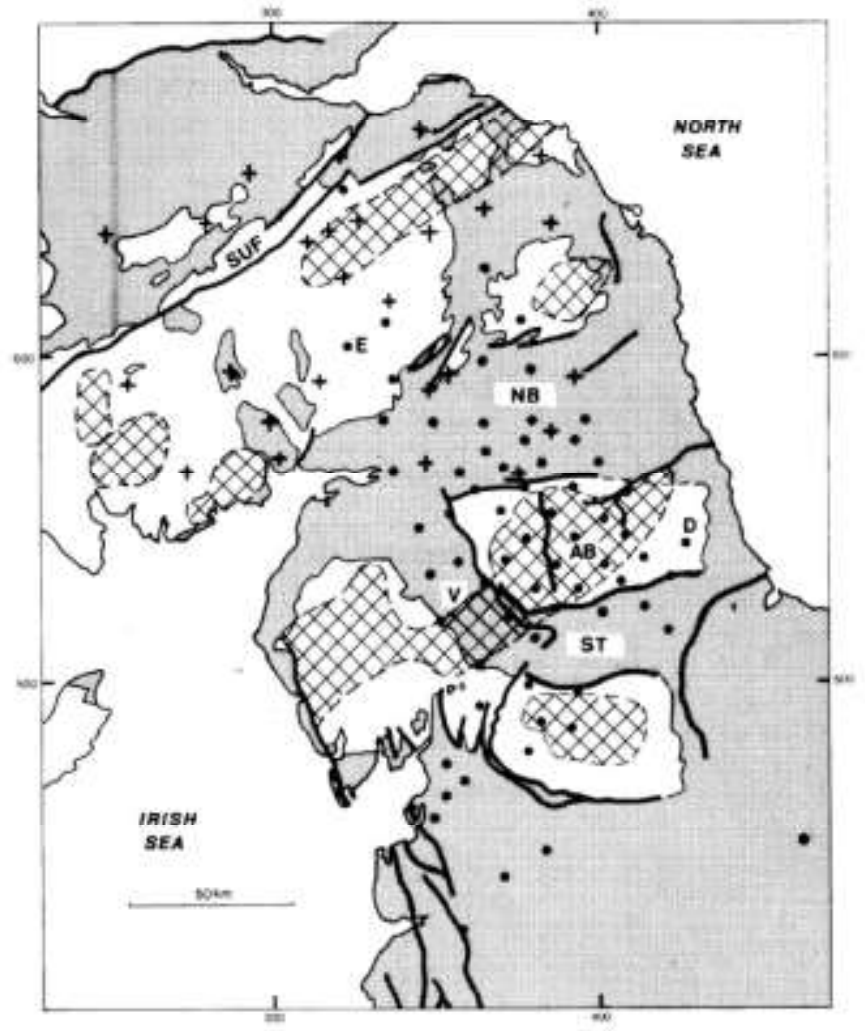

Fig. 1 Magnetometer sites used in the analysis: +, published data ${ }^{3,4,13} ; 0$, unpublished data; - major faults. Cross-hatching indicates areas underlain by granite batholiths. Stippled areas are underlain by substantial thicknesses of post-Caledonian sedimentary rock. SUF, Southern Uplands Fault; NB, Northumberland Basin; AB, Alston Block; V, Vale of Eden; ST, Stainmore Trough; E. Eskdalemuir; D. Durham. 
the equivalent current system at a depth of $5 \mathrm{~km}$ derived from the vertical field map in Fig. 2. Because of the limitations in the analysis (the effect of anomalous horizontal fields that we have been forced to ignore, and the fact that the current is not necessarily concentrated at a single depth), Fig. 3 must be regarded as an aid to visualization of the anomalous structures, rather than a basis for quantitative interpretation.

The most interesting features in Fig. 3 are those regions where the sheet of current is concentrated by narrow belts of relatively highly conducting rock in the crust. It appears that this polarization of the source field does not give rise to detectable fields arising directly form current concentrations in the shallow seas. Instead, the current is enhanced in two principal linear features through the land: one which runs from north-east to south-west across the Southern Uplands, with its axis to the south-east of the Southern Uplands Fault, and the second which runs from east to west through the Northumberland Basin, between the North Sea and the Solway Firth.

Previous workers ${ }^{3-5}$ have defined and commented on the first of the two anomalies. Its direction is parallel to that of the Caledonian structures, but it does not coincide with any known belt of conductive rock close to the surface. Unfortunately, the station spacing in this region is often quite large and irregular, and the vertical field map does not impose very strong constraints on the depth of the current system. Magnetotelluric measurements have been made in the Southern Uplands ${ }^{11}$, but, because they cover a relatively narrow band of frequencies, their resolution of upper crustal structure is poor. In the lower crust and upper mantle, they indicate a conductive zone at depths between 20 and $70 \mathrm{~km}$. The cause of the high conductivity is unclear, although it has been suggested that it may be due in part to the presence of hydrated rocks and dehydration at the amphibolite-granulite transition ${ }^{12,13}$.

Although the Northumberland Basin anomaly merges with the Southern Uplands anomaly at its western end, it is completely separate in the east. Note that the magnetic observatory

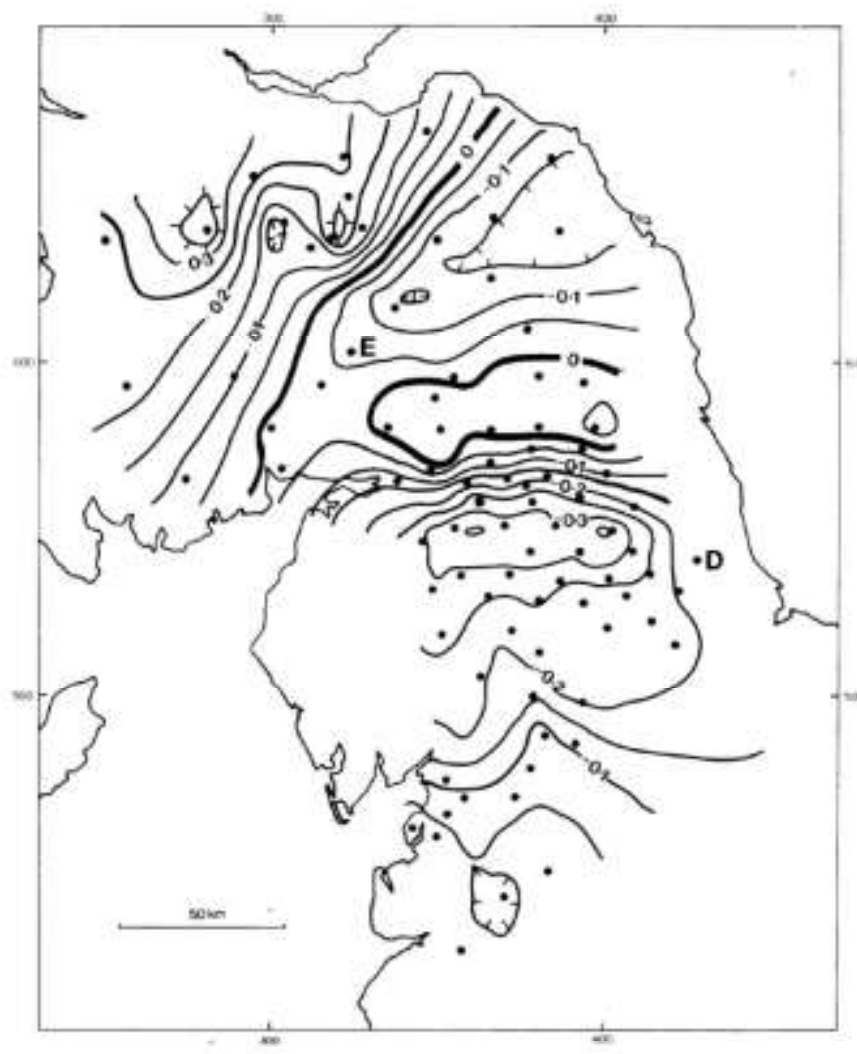

Fig. 2 Map of the in-phase part of the vertical magnetic field produced when the horizontal field is directed towards magnetic north $\left(9^{\circ} \mathrm{W}\right)$, and has unit amplitude.

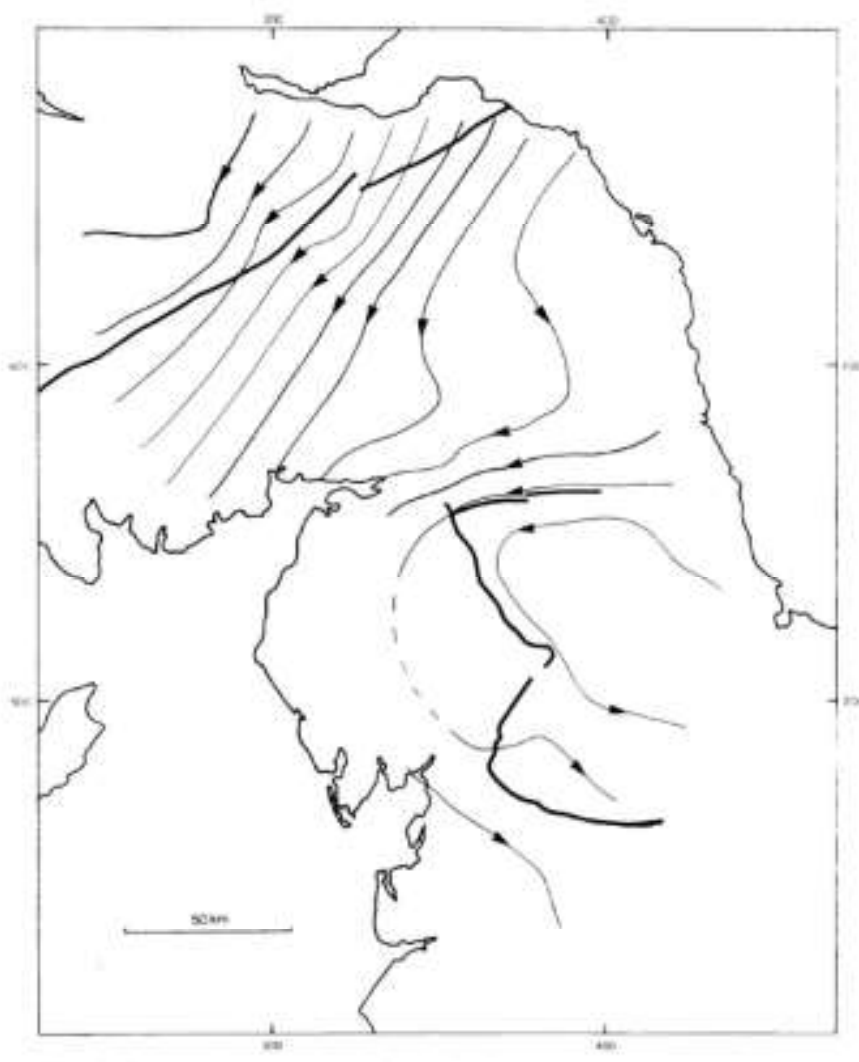

Fig. 3 The current stream function in a thin sheet at a depth of $5 \mathrm{~km}$, derived from Fig. 2. Approximately 10 A flows between the stream lines when the amplitude of the horizontal magnetic field is $1 \mathrm{nT}$.

at Eskdalemuir, where the anomalous character of the variation fields was first detected, lies where the anomalous fields of the two structures merge. The Northumberland Basin anomaly is very well defined by the dense network of IGS/Lancaster stations. The southern edge of the anomalous current concentration coincides with the northern margin of the Weardale granite, which underlies the Alston Block. When the current sheet is placed at depths in excess of $5 \mathrm{~km}$, the current stream function becomes unstable, indicating that at least part of the actual current is shallower than $5 \mathrm{~km}$. Magnetotelluric measurements at a site in the Northumberland Basin ${ }^{11}$ also indicate a shallow conductor, although they are not conclusive because the sounding is close to the southern margin. The variation in depth of the pre-Carboniferous basement within the basin has been established by seismic refraction and gravity surveys ${ }^{14}$. The sediments are at their thickest (up to $3 \mathrm{~km}$ ) towards the southern margin, where the current density is greatest. Taken together, these facts suggest that the current responsible for the magnetic variation anomaly is concentrated principally in the relatively conductive Carboniferous sedimentary rocks of the Northumberland Basin.

To the west of the Alston Block, in the Vale of Eden, is a similar sedimentary basin which runs in a north-south direction, and which contains up to $3 \mathrm{~km}$ of Carboniferous and PermoTriassic sediment ${ }^{15}$. If these sedimentary basins responded to electromagnetic fields as isolated conductors, the maximum response of the Vale of Eden should occur when the regional current flow is north-south, that is the horizontal magnetic field is east-west. However, at $750 \mathrm{~s}$ period, the basin responds to neither azimuth of the field, in striking contrast to the Northumberiand Basin. What differentiates the two basins are the links which the Northumberland Basin makes at either end to the laterally extensive conductors of the Irish and North seas, together with their own associated sedimentary basins. The Vale of Eden is isolated at its southern end, either by the postulated ridge connecting the Lake District and Weardale 
granites ${ }^{15}$, or by the westward thinning of sediments in the Stainmore Trough.

It has been suggested that the Northumberland Basin marks the Iapetus suture, the line of closure of the proto-Atlantic Ocean ${ }^{7}$. Before it can be established that there is a deep conductive structure beneath the basin, it will be necessary to model the effects of the currents in the shallow sedimentary rocks, using the available data on their thickness. We believe that, if the response of the Basin to electromagnetic fields with periods of $750 \mathrm{~s}$ is to be correctly modelled, it will be essential to include the Irish and North Seas and their underlying sediments.

1. Law, L. K. \& Riddincough, R. P. Can. J. Earth Sci. 8, 1094-1106 (1971).

2. Bailey, R. C. \& Edwands, R. N. Geophys. J. R. asin. Sac, 45, 97-104 (1976)

3. Hutton, V. R. S. \& Jones, A. G. Adv. Eank planet Sci. 9, 141-150 (1980).

4. Huttan, V. R. S. et al. Phys. Farih planet. Inter. 24, 66-87 (1981)

Edwards, R. N., Law, L. K. \& White, A. Phil Thans. R. Soc. 270, 289-323 (1971).

6. Grimes, D. L. F, thesis, Univ, Lanchster (1977),

7. Anderton, R., Bridges, P. H., Leeder, M. R. \& Sellwood, B. W. A Dymamic Senerigraphy of the Brisish Lsies (Allen \& Unwin, Edinbutah, 1979).
Without the results from such modelling, all we can say at present is that a deep conductor beneath the basin does not seem essential. The only completely unexplained feature of the maps is the Southern Uplands anomaly, and, if we believe that the line of the suture must be marked by a conductivity anomaly, this must be reckoned the most likely candidate.

We gratefully acknowledge the support of the NERC in the form of grant GR3/2371 and a grant from the Deep Geology Project. This paper is published with the approval of the Director, Institute of Geological Sciences (NERC).

8. Baniks, R. I. Phys. Farth planer. Inier. 7, 339-348 (1973)

Bailey, R. C, Edwards, R. N., Gartand, G. D., Kurtz, R. \& Fitcher, D. J. Geomags Groelect. 26, 125-146 (1974)

10. Banks, R. J. Geophys. J. R. ast. Soc, S6, 139-157 (1979)

11. Jones, A. G. \& Hutton, V, R. S. Geophys, J, R. aser Soc, 56, 329-368 (1979).

12. Hutton, V. R. S., Ingham, M. R. A Mbipom, M. W. Nature 287, 30-33 (1980)

13. Ingham, M. R. \& Hutton, V. R. S. Geophys. J. R. ars. Soc 69, 595-606 (1982)

14. Lee, M. K. Geophys. J. R. ast, Soc. 69, 281 (1982).

15. Bott, M. H. P. J. geol. Soc. Lond. 113, 93-117 (1974) 